\title{
The Sales funnel in Unit-economy indicators as an effective tool of Technological Entrepreneurship
}

\author{
Elena V. Vasilieva \\ Department of Business Informatics \\ Financial University under the Government of the Russian Federation \\ Moscow, Russia \\ evvasileva@fa.ru
}

Abstract. An entrepreneur who is looking for the best strategy to promote their products and services in the digital markets should understand that Internet entrepreneurship, like any kind of activity, is subject to certain laws of management, Economics, marketing, require a thorough analysis of competitiveness, the study of performance metrics and conduct a deep behavioral analysis. The study of the characteristic levels of the sales funnel, and the main strategies for the management of the product funnel, the technique of design and analysis of grocery funnel using metrics, Unit Economics, as a new method of economic modeling to assess profitability on the basis of one business unit. Highlighted features of the strategy development funnel selling by the method of Critical Chain Management and Theory of Constraints. A method of finding bottlenecks in the sales funnel is proposed, which consists in a consistent assessment of the impact on the profit of each of its five basic metrics, for each of which there are development tools that allow you to find points of rapid profit growth.

Keywords: strategy, management, product management, Internet technologies, digital markets, design thinking.

\section{INTRODUCTION}

According to Global Digital, the number of users of Internet resources in the world by 2018 reached 4,021 billion people. In December 2018, the international telecommunication Union published the report "Measuring the information society", which confirmed that more than half of the world's population $(51.2 \%)$ is permanently connected to the global network [1]. The top ten world leaders in the conditional ranking of the number of the Internet audience includes China with 668 million users ( $51.98 \%$ of the total population), India -350 million $(26.0 \%)$, USA -277 million (85.1\%), Japan - 110 million ( $87.3 \%$ ), Brazil 110 million (52.4 per cent), Russia - 87.5 million (59.8\%), and Germany - 72 million (86.7\%), Indonesia 71 million (26.7\%), Nigeria - 70 million $(35.8 \%)$, Mexico -59 million (45.4\%). At the Russian investment forum in Sochi on February 27, 2017, the audience of Runet (Russian Internet zone) was announced - 86 million people [2]. In 2018 according to the Russian Association of electronic communications, the number of users of Runet has reached 90 million people, and mobile audience continues to grow (24.3 million people), ahead of the desktop (13.9 million people) [3].

Many aspiring entrepreneurs who are just going to enter the digital markets with their project have too much confidence that the "blue ocean "of the" Internet" [4] is completely free from competition. It is also a common misconception that the consumer is always open to innovation, ready to pay any price just to become the first owner of a unique product. However, it is necessary to understand that Internet entrepreneurship, like any kind of activity, is subject to certain laws of management, Economics, marketing. This poses a challenge for the entrepreneur to explore new approaches to product management in digital markets. including business description in unit-economy metrics.

\section{THE DIGITAL PRODUCT SALES FUNNEL MANAGEMENT}

The concept of "Consumer funnel" was coined by E. St. Elmo Lewis in 1898, and today it has become the norm for an entrepreneur to think in terms of a sales funnel. Using a funnel any journey, customer, user, opponent, reader, etc., can be visualized if it involves a multistage pro- 
cess: from his acquaintance with the service, the terms of talks (first contact with the product) to the final stages of achieving results and finding the balance of interests of buyer and seller. In the form of a funnel, thus, visually you can imagine almost any model of the efficiency of the business system. Sales funnel (other names-purchase funnel, sales pipeline) - a model of distribution of buyers by stages of the process of selling a product or service from attracting the attention of a potential consumer to the proposal until the completion of the transaction (purchase).

Sales management is the process of transferring the status of the buyer from "potential" to "buyer who paid money". If the definition of the equilibrium market price is the concept of finding a balance between the interests of the conflicting parties, the funnel, as a tool of analysis, can also be used not only in sales. This process consists of a series of steps that can be graphically represented as an inverted pyramid, with a wide edge at the top, where the interest of the potential buyer is represented, and a narrow neck at the bottom, where the number of purchases of the proposed product is shown. The customer is passed through the sales funnel from familiarization with the product to its purchase. The result of the passage of a particular level of the funnel, the transformation (conversion) of visitors into buyers, etc., expressed through conversion (eng. convertion rate is the "speed conversion"). The analogue of conversion in traditional approaches to assessing the efficiency of production is the efficiency coefficient.

A typical site has many conversion points, from tags and subscription widgets to pop-up and chatbots. Measurements of the number of visitors at each level of the funnel allow you to track analytical tools such as: "Yandex.Metric", Google Analytics, MixPanel and other Resources of Google Analytics and Google Adwords track conversion in the contextual advertising system. Also, statistics of the addresses and requests which have come to mail, calls is collected. To get a complete picture of the success of sales, management statistics analysis is carried out by week and month. This allows you to determine at what stage of the funnel customer losses occur.

Speaking about Internet-store, it is logical to distinguish three levels: passer-by, visitor, buyer. However, you can visualize the funnel in more detail in the following example (Fig. 1).

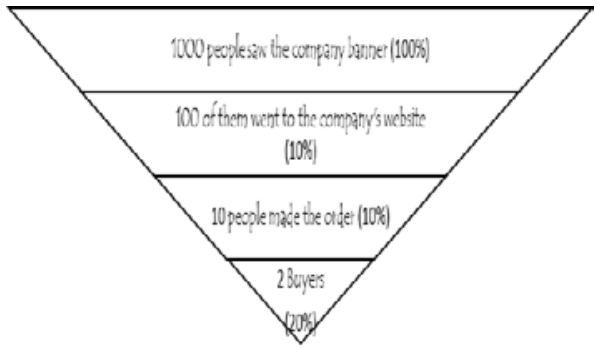

Fig. 1. Shop sales funnel

The company's banner was seen by 1,000 people (stage I funnel). Of those who saw 100 people came to the site (II stage funnel conversion banner advertising 10\%). Of these, 10 people made the order ( $10 \%$ conversion). But only two paid (made a purchase) - the IV stage of the funnel with a conversion of $20 \%$.

Funnel performance is useful to compare with the overall performance of the market and competitors. The data obtained on conversion and other funnel metrics (for example, the average check or the average number of sales for the period) are compared with the average in the market segment, but this can only give an approximate assessment of the success of the business, since it is not reasonable to compare the characteristics of a unique enterprise with the figures of statistics, mostly obtained from untested and often dubious sources.

The results of the funnel level evaluation can be compared with the performance of previous periods or another point of sale of your network. If the conversion is regularly measured and examined in the dynamics, it allows you to assess the effectiveness of certain measures to improve 
the processes at each stage of the funnel or to determine the "bottlenecks" of the sales process. In this case, conversion becomes one of the main characteristics of management.

\section{SALESFUNNELMANAGEMENTSTRATEGIES}

Continuous analysis of the funnel provides a clear picture of the strengths and weaknesses of doing business. The purpose of building a funnel is to give an idea of the correctness of the chosen strategy for the main tasks: to attract, retain and grow physical channels. We emphasize the usefulness of the funnel and its analysis: funnel allows you to evaluate the behavior of the target audience (website, Internet platform, point of sale); allows you to competently build the entire process of interaction with a potential buyer; provides an opportunity to present for analysis the conversion of a certain level, and in General; helps to identify the "weak link" in the sales chain; helps to model different sales strategies and predict overall business performance.

The peculiarity of funnel management is the complexity of comparing the various activities that are necessary to promote the visitor of the site through the funnel to the level of "purchase". At the entrance of the funnel is the number of potential buyers, to attract which are the main costs of the company (advertising, bonus system, etc.), but the financial results (income, profit of the company) are provided by visitors who make a purchase, located at the bottom of the funnel. And at the same time at each level of the funnel for the successful completion of the transaction (sale), various optimization options are possible:

A). the cost of creating an interesting offer and attracting visitors to the company's page (marketing);

B). the attractiveness and convenience of the web page to increase the interest of the visitor and promotion to pay (SEO);

C). sales processes, including ease of cart management and ease of payment and delivery.

Funnel construction divides the entire process into separate clusters. Each of them has its own local goal, different from the global goal - "to sell the goods". For example, the purpose of contextual advertising is to sell a click, the transition to the site. The purpose of the advertising design is to sell a store visit. All of these targets sell a key level. When the business is presented as a narrow cluster, efficiency increases. That is why it is so important to carry out various measures to improve the processes of each stage of the funnel passage by a potential buyer, to increase the conversion of each level in order to get more interested in the offer at the entrance, and then not to lose them, but to bring them to the purchase (transaction).

Among the ways to control the funnel are the following.

1. Proportional funnel expansion: increasing traffic at the entrance of the funnel, getting a large conversion, the seller expands the funnel in the following stages and increases the result at the exit.

2. Stretching involves increasing conversion at each level, not just at the top.

3. Key level. The funnel level, which is the limit of the entire sales system, is determined, and then actions are performed to increase the conversion rates of this level (increase the number of people who have reached this level).

In practice, the number of visitors can be increased through competent research of the target audience, promotion of information to it, contextual advertising, banners, affiliate links, targeted advertising in social networks, personalization of the offer. And at each level of the funnel it is necessary to pay attention to the motivation and remuneration system of people responsible for this level.

\section{UNIT-ECONOMICS IN SALES FUNNEL ANALYSIS}

Work with funnel levels and analysis of financial performance indicators of the sales process is carried out with the help of unit-economy. Unit Economics is a method of economic modeling used to determine the effectiveness of a digital business model by evaluating the profitability of a unit of goods or a single customer. This is the economy of a single transaction. The author term 
and set of rules - D. Skok $[5 ; 6]$. This is a new scientific discipline, the main positions of which are still being studied and tested in practice.

The key principle of the analysis of the sales funnel in the unit-economy metrics is that the business can be successful only if each individual unit of goods or services will be profitable. Analysis of the effectiveness of the work personally with each of our clients based on metrics, unit economy, of course, the priority is more for B2B sales than B2C. In B2C not each buyer and the number of sales that is important, butthe mass buyer. This is the sector of large grocery stores, most online stores. The main metrics of the unit-economy: revenue per period per customer and in terms of one visitor attracted to the site, the average check, the cost of attraction, etc. The B2B sector, as a rule, works under personal ("manual") sales to order. It is characterized by individual development, high average check and good margins, as several customers provide the main revenue of the company.

The unit-economy model is well suited for making mathematically correct balanced decisions. It analyzes only 5 basic metrics, for each of which there are clear and understandable development tools that allow you to find points of rapid profit growth. The task of the analysis is to compare different growth strategies, test them in practice over a period of time (for example, a week), evaluate the results and focus on the best. Even in a seemingly successful business, there will be at least one bottleneck in the sales funnel. This can be a conversion from one level of the funnel to the next, or a place that does not allow you to scale the business.

Problems of most Internet projects occur when launching a new strategy in the market, changing all the parameters of the advertising campaign trying to improve the conversion rate at each level of the funnel and increase traffic, while simultaneously reducing the cost per click, raise prices, change the site interface, etc. In the end, there are difficulties in understanding what events had a stronger impact on financial results. According to the Theory of Constraints [7; 8], it is necessary to find the bottleneck of the process that restricts the entire business system, and then maximize its performance. This limitation is precisely the parameter that, with the least effort, will give the maximum growth, or those who most restrain it. A bottleneck in the sales process means that you cannot, while maintaining profitability, increase the number of customers going through this limitation in the funnel because you have exceeded your production or marketing capabilities.

The easiest way of finding bottlenecks in the sales funnel is a consistent estimate of the effect on profit of each of the metrics of funnel: number of visitors to the top of the funnel; their conversion to orders and customers, etc. the loss of conversion can influence the usability of the site, the terms and conditions of the purchase process, incorrect value offer or discount, ill-conceived user path from the time of selection of goods in the basket before payment method, and then the delivery options and the provision of after-sales service.

Therefore, they formulate possible development scenarios, determine which parameter change has affected the increase in profits to a greater extent, and depending on this, prioritize the implementation of each of the scenarios. Then, in turn, test each of the scenarios in practice, comparing the predicted and real results. The Internet environment, on the one hand, allows you to immediately conduct an experiment and collect data for further study and selection of the best scenario. But, on the other hand, the speed of reaction of buyers, competitors and responses of the whole environment of the strategy implementation forces to conduct the experiment in a short time and make decisions quickly, making adjustments to the business model. Also, keep in mind that when you find a way to remove one constraint, a new constraint usually occurs in the next funnel steps. Therefore, the process of optimizing the sales process is iterative and regular.

Now, when thanks to the global network, any product, information about which is published on the Internet, will find its buyers sooner or later anywhere in the world, the key to sales lies in a deep study of the needs and pains of the target consumer, finding their motives for buying. The creation of a profile of the target customer-developed innovation helps to understand the needs of the prospective customer, client, service user, to trace specific aspects of his character, identify his priorities in life that will allow you to identify the most relevant values in your solution. 
Creating a portrait of a potential user will help tools Design Thinking. Works [9-15] are devoted to this approach.

\section{CONCLUSION}

Before starting any business, including on the Internet, it is necessary to set a clear goal, consider ways to achieve it, calculate all the risks and generally form a concept for the development of the future organization. That is why the approach to drawing up a digital transformation strategy based on the sales funnel is so relevant today. The digital environment gives a lot of chances, but also requires new knowledge and competencies from the entrepreneur to be able to build a sustainable business in a world of uncertainty, speed and risk.

\section{REFERENCES}

[1]. Internet 2017-2018 v mire i v Rossii: statistika i trendy [Internet 2017-2018 in the world and in Russia: statistics and trends]. (In Russian.) Available at: https://www.web-canape. $\mathrm{ru} /$ business/internet-2017-2018-v-mire-i-vrossii-statistika-i-trendy/.

[2]. Ob'em ekonomiki Runeta prevysil 1,5 trln rublei [The economy of the Runet exceeded 1.5 trillion rubles]. (In Russian.) Available at: https://tass.ru/ekonomika/4053755.

[3]. Ob'em rossiiskogo rynka internet-kommertsii sostavlyaet 2 trln rub. [The volume of the Russian Internet commerce market is 2 trillion rubles]. (In Russian.) Available at: https:// tass.ru/ekonomika/5816762.

[4]. Chan K. V., Moborn R. Blue ocean strategy. Strategiya golubogo okeana. Kak sozdat'svobodnuyu rynochnuy nishu I perestat' boyat'sya konkurentov [How to create a free market niche and stop being afraid of competitors]. Moscow: Mann, Ivanov and Ferber, 2016. (In Russian.)

[5]. Skok D. Customer Acquisition: Maximizing your Funnel. Available at: https://www.forentrepreneurs.com/sales-funnel/.

[6]. Skok D. Udalenie uzkikh mest voronki prodazh. Optimizatsiya protsessa privlecheniya klientov [Remove bottlenecks in sales funnels. Optimization of the process of attracting customers]. Available at: https://www.forentrepreneurs.com/sales-funnel/(accessed 20.05.2019). (In Russian.)

[7]. Goldratt E. M., Tsel' C. J. Protsess nepreryvnogo sovershenstvovaniya [The goal: a process of ongoing improvement]. Minsk: Potpourri, 2009. (In Russian.)

[8]. Lich L. Critical chain project management. Boston; London: Artech House, 2014.

[9]. Kelley T., Kelley D. Creative Confidence Unleashing the Creative Potential Within Us All. NY: Barnes \& Noble, 2013.

[10]. Liedtka J., Ogilvie T. Designing for Growth: A Design Thinking Toolkit for Managers. NY: Columbia University Press, 2011.

[11]. Clark T., Osterwalder A., Pigneur Y. Business model you: a one-page method for reinventing your career. New Jersey: John Wiley \& Sons, 2012.

[12]. Blank S., Dorf B. The Startup Owner's Manual: The Step-By-Step Guide for Building a Great Company. Palo Alto: K\&S Ranch Press, 2012.

[13]. Ries E. The Lean Start-up: How Today's Entrepreneurs Use Continuous Innovation to Create Radically Successful Businesses. NY: Crown Business, 2013.

[14]. Kotler P., Kartajaya H., Setiawan I. Marketing 3.0: From Products to Customers to the Human Spirit. NY: John Wiley \& Sons, Inc., 2010.

[15]. Vasilieva E. Design thinking: a little bit about the approach and a lot about the tools of creative thinking, learning client requests and creating ideas. Moscow: RU-SCIENCE, 2018. (In Russian.) . 